\section{Can state ownership of the tobacco industry really advance tobacco control?}

\author{
Angela Pratt
}

Could state-owned tobacco industries help take us towards the tobacco end-game? The thought that the tobacco industry be put to work to advance progressive tobacco control policies is usually anathema for tobacco control experts and advocates. After all, the WHO Framework Convention on Tobacco Control (FCTC) is based on the premise that there is an irreconcilable conflict between the tobacco industry and public health. However, this is what Hogg et $a l^{1}$ ask us to consider in their recent paper on whether state-ownership of the tobacco industry is in fact a fundamental conflict of interest, or a 'tremendous opportunity' for tobacco control.

In their thought-provoking analysis, Hogg et al argue, first of all, that state-owned tobacco companies (SOTCs) are seriously under-analysed in the academic literature on the tobacco industry. They have a point: despite the fact that China National Tobacco Corporation (CNTC), for example, has a greater share —at $43 \%$ - of the global tobacco market than Philip Morris International (14\%), British American Tobacco (12\%), Japan Tobacco International (9\%) and Imperial (5\%) combined, ${ }^{2}$ Tobacco Control has published just three articles on CNTC, compared to around 70 on Philip Morris alone. $^{1}$

Hogg et al propose three contrasting perspectives for assessing the strategic significance of state-ownership of tobacco companies to tobacco control. First, the 'intrinsic conflict' model, in which the tobacco industry-state-owned or not-is seen as having an irreconcilable conflict of interest with public health. Using this perspective, it is sometimes argued that SOTCs should be privatised, because the fundamental conflict of interest created by a government both owning and regulating the tobacco industry cannot otherwise be resolved. However, as Gilmore et al have pointed out, privatisation often leads to 'increased marketing, more effective

Correspondence to Dr Angela Pratt, World Health Organization, Unit 401, 23 Dongzhimenwai Ave, Chaoyang District, Beijing 100600, People's Republic of China; pratta@who.int distribution and lower prices, creating additional demand for cigarettes among new and existing smokers, leading to increased cigarette consumption, higher smoking prevalence and lower age of smoking initiation'. 3 Be careful what you wish for.

The second perspective is that the conflict of interest between SOTCs and public health can be 'institutionally mediated', for example through the establishment of a legislative 'firewall' separating the arm/s of government responsible for tobacco control policy from those responsible for the tobacco industry, as is now the case in Thailand. Viewed within this framework, the problem in China is not that CNTC is an SOTC per se, but the fact that the same Ministry (Industry and Information Technology, MIIT) which is responsible for increasing tobacco profits is also responsible for coordinating implementation of the WHO FCTC. This conflict could be mitigated, or institutionally mediated, by, for example, removing responsibility for overall WHO FCTC implementation and specific policy issues like package warning labels, from MIIT.

According to the third perspective, 'interest alignment', rather than necessarily representing an inherent threat to tobacco control, SOTCs could in fact be co-opted into advancing the goals of tobacco control-by virtue of their potential to play a role in addressing supply side issues. In the most optimistic version of this scenario, a national government could essentially instruct its SOTC to 'sunset' itself, or wind up tobacco production over time, thereby dramatically reducing-even eliminating-the supply of tobacco products in a particular country.

It is a tantalising prospect. However, could it really work like this? Hogg et al raise a number of issues that provide food for thought.

For instance, the authors argue that the example of Nordic alcohol monopolies being tasked with reducing harm from alcohol consumption provides an example of how this strategy can work in practice. However, there is an important difference between alcohol and tobacco: current debates about products such as e-cigarettes aside, there is no harm reduction discussion to be had about tobacco per se. And therefore, there is no conversation to be had with the tobacco industry — state-owned or otherwise-about harm reduction. It seems, then, that the only way of getting past the fundamental conflict of interest is the most optimistic version of the interest alignment model mentioned above-that is, governments charge their SOTCs with devising a strategy to 'sunset' themselves. However, is this politically feasible?

The answer to this may lie, at least in part, in alignment of economic, rather than purely public health, interests-that is, in showing that the combined costs of tobacco use (in the form of healthcare costs, reduced productivity and participation, and so on) far outweigh any economic benefits to the government and the country more broadly. Where a government's top political leaders are convinced that this is the case, it potentially becomes more conceivable that the same government could decide that its SOTC is doing its country more harm than good and take steps to act on this.

However, the real impact of the 'interest alignment' framework will to a large extent depend on the dynamics of the tobacco market in each country. Not all SOTCs are created equal, and not all SOTCs are monopolies. In some countries the state is more an investor than an owner: for instance Japan, where the tobacco industry is not a governmentowned enterprise but a private company in which the government holds a significant $(30 \%)$ interest. ${ }^{1}$ In other places there is a complex mix of public and private interests. Take Cuba for example, where the Government controls the domestic market, but Souza Cruz (a subsidiary of British American Tobacco) and Tabacalera (a subsidiary of Imperial Tobacco) each have an important stake in Cuban tobacco's foreign currency and international businesses through joint venture arrangements with the government-owned Cubatabaco. $^{4}$ In Thailand, the SOTC dominates the industry but multinational companies compete for market share especially at the 'premium' end of the market ${ }^{5}$ - presumably limiting the government's capacity to align interests. Even in China where there is an effective monopoly, Marlboro cigarettes are produced by CNTC under license with Philip Morris International. ${ }^{6}$ This kind of contractual arrangement could affect an SOTC's options. How then would the 'interest alignment' framework work in each of these very different contexts, especially 
taking into account the complex web of vested interests in which the tobacco industry operates in many countries?

The capacity for a government to use its SOTC-or its interest in a private tobacco company, for that matter-to reduce tobacco supply to its domestic market may be further complicated by the existence of international (bilateral and multilateral) trade and investment agreements. Such agreements could have a bearing on any regulatory measures which are able to be construed as barriers to trade. $^{7}$ Countries would also need to assess their WTO obligations in the context of any specific proposals to reduce domestic tobacco supply.

Finally, what would be the implications for implementation of the WHO FCTC? Noting the discussions at the sixth Conference of the Parties (COP) on tobacco industry interference and the need to strengthen implementation of Article 5.3, is there scope to consider 'interest alignment' thinking in the context of further discussions on this topic at the seventh COP? Though of course, it must be noted that any change to the WHO FCTC or its Guidelines would require agreement among the Parties, including those with SOTCs.

Hogg et al conclude by suggesting that interest alignment with SOTCs may provide an 'alternative route' to the tobacco end game. However, an alternative to what?

Proven tobacco demand-reductions measures-such as smoke-free public places, higher taxes, tobacco marketing bans, large graphic warning labels and cessation support for smokers who need help to quit-must continue to be vigorously pursued. In a country like China with its more than 300 million smokers, these measures provide the only real prospect of lowering the country's alarmingly high smoking rate in the near and medium terms.

However, the prospect of finding a path through which these measures could be implemented in conjunction with a robust long-term supply side strategy, is an enticing prospect indeed-and certainly worthy of further analysis, discussion and debate.

Twitter Follow Angela PRATT at @angepratt

Competing interests None declared.

Provenance and peer review Commissioned; internally peer reviewed.

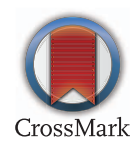

To cite Pratt A. Tob Control 2016;25:365-366.

Published Online First 5 October 2015

\section{SLinked}

http://dx.doi.org/10.1136/tobaccocontrol-2014052114

Tob Control 2016;25:365-366.

doi:10.1136/tobaccocontrol-2015-052594

\section{REFERENCES}

1 Hogg SL, Hill SE, Collin J. State-ownership of tobacco industry: a 'fundamental conflict of interest' or a 'tremendous opportunity' for tobacco control? Tob Control 2016;25:367-72.

2 Campaign for Tobacco Free Kids. The Global Cigarette Industry. August 2014. http://global.tobaccofreekids. org/en/industry_watch/industry_profiles/companies/ (accessed 7 Sep 2015).

3 Gilmore $A B$, Fooks G, McKee M. A review of the impacts of tobacco industry privatisation: implications for policy. Glob Public Health 2011;6:621-42.

4 Buck T. Spain's Tabacalera set to take the cigar in US amid Cuba détente. Financial Times June 162015. http://www.ft.com/intl/cms/s/0/26197be6-110c-11e59bf8-00144feabdc0.html\#axzz3|3ieYLsB (accessed 9 Sep 2015); Souza Cruz website: http://www.souzacruz. com.br/group/sites/SOU_7YKDBY.nsf/vwPagesWebLive/ D07V9KFS?opendocument (accessed 9 Sep 2015).

5 Euromonitor International. Tobacco in ThailandCountry Report [web summary]. February 2015. http:// www.euromonitor.com/tobacco-in-thailand/report (accessed 9 Sep 2015).

6 Campaign for Tobacco Free Kids. China National Tobacco Corporation and Philip Morris International's Partnership. April 2010. http://global.tobaccofreekids. org/en/industry_watch/industry_profiles/companies/ (accessed 7 Sep 2015).

7 World Health Organization. Confronting the tobacco epidemic in a new era of trade and investment liberalization. Geneva, Switzerland, 2012. 